\title{
Optimization of energy consumption and thermal comfort for intelligent building management system using genetic algorithm
}

\author{
Subhi Aswad Mohammed, Osama Ali Awad, Abdulkareem Merhej Radhi \\ College of Information Engineering, Al-Nahrain University, Baghdad, Iraq
}

\begin{tabular}{|c|c|}
\hline Article Info & ABSTRACT \\
\hline Article history: & This paper presents a design, simulation and performance evaluation of an \\
\hline Received Feb 11, 2020 & $\begin{array}{l}\text { del for the Heating, Ventilation and Air-Conditioning (HVAC) } \\
\text { intelligent control algorithm. Fanger's comfort method and }\end{array}$ \\
\hline Revised Apr 15, 2020 & genetic algorithms were used to obtain the optimal and initial values. The heat \\
\hline Accepted May 11, 2020 & $\begin{array}{l}\text { transmission coefficient between internal and external environments were } \\
\text { determined depending on several inputs and factors acquired via supervisory }\end{array}$ \\
\hline Keywords: & $\begin{array}{l}\text { control and data acquisition (SCADA) system sensors. The main feature of the } \\
\text { real-time model is the prediction of the internal buildings environment, in }\end{array}$ \\
\hline Energy consumption & order to control HVAC system for indoor environment and to utilize the \\
\hline Fanger's thermal comfort & $\begin{array}{l}\text { optımum power consumed dependıng on optımized air temperature value. The } \\
\text { predicted air temperature value and Predictive Mean Vote (PMV) value was }\end{array}$ \\
\hline Genetic algorithm & applied using intelligent algorithm to obtain an optimal comfort level of the air \\
\hline HVAC & temperature. The optimized air temperature value can be used in HVAC \\
\hline IBMS & system controller to ensure that the temperature of indoor can reach a specific \\
\hline PMV & value after a known period of time. The use of genetic algorithm (GE) ensures \\
\hline SCADA & $\begin{array}{l}\text { that the used power is well below its peak value and maintains the comfort of } \\
\text { the user's environment. }\end{array}$ \\
\hline
\end{tabular}

Copyright () 2020 Institute of Advanced Engineering and Science. All rights reserved.

Corresponding Author:

Subhi Aswad Mohammed

Department of System Engineering,

College of Information Engineering,

University of AL-Nahrain, Baghdad- Iraq

Email: subhiaswad1958@gmail.com

\section{INTRODUCTION}

The increasing demands for building services and human comfort levels have spurred reducing energy consumption of HVAC systems inside smart buildings. In order to monitor and control the optimal parameters, the buildings will be equipped with SCADA systems to control HVAC, energy management, optimization, and comfort requirements of the occupants. The environmental comfort is strongly related to the occupants' satisfaction and productivity. The quality of life in buildings is determined by three basic factors; thermal comfort, visual comfort, and indoor air quality. Thermal comfort is determined by the predictive mean vote (PMV) index which is calculated by Fanger's equation [1].

This paper integrates the use of SCADA systems with the intelligent buildings management system (IBMS) in order to optimize the power consumption used to run HVAC systems. The use of genetic algorithms, Fanger's approach, and the calculations of heat transmission coefficient between controlled room were very effective techniques used to predict and then to control HVAC system's power requirement. SCADA systems are used to monitor and control a plant or equipment in industries. SCADA systems were built with distributed control system capabilities and customized based on certain proprietary control features built-in by the designer [2].

There are many HVAC system implementations and thermal comfort approaches in literature. In 2014, controlling HVAC system with the purpose of maintaining a desired thermal comfort level is introduced, whilst minimizing the electrical energy required. The model based predictive control (MBPC) methodology uses 
predictive models, implemented by radial basis function neural networks, and identified by means of a Multiobjective genetic algorithm (MOGA). This approach is robust, and able to obtain energy savings greater than $50 \%$ [3]. In 2017, an artificial neural network (ANN) based model predictive control (MPC) system is used to supervisor the HVAC system. The MPC generated the dynamic temperature set-point of the zone air resulted in the operating cost reduction of the equipment without violating the thermal comfort constraints [4]. In 2018, a data driven arrangement is presented for the energy and comfort controlling in large constructions with compound regions and dynamic residence configurations. The method developed a multi-variable paradigm through structural equation modeling (SEM) so as to find the effects of thermal combination among the neighboring areas, residence and the external environment variations on the thermal performance of the building sectors. This control strategy is employed for the HVAC system [5]. In 2019, a self-tuned HVAC controller is presented with model predictive control (MPC) forming a closed-loop that offers adapted thermal environments to satisfy resident preferences while reducing energy depletion, and the application of this controller in a real occupied workplace [6].

\section{INTELLIGENT BUILDING MANAGEMENT SYSTEM}

The intelligent building Management System is an integrated solution for energy management systems, automation and life-safety. IBMS is managing the building based and integrates different systems and devices, into a unified platform that can be controlled in real time application. The requirements for the system architecture and IBMS integration are presented in Figure 1 [7].

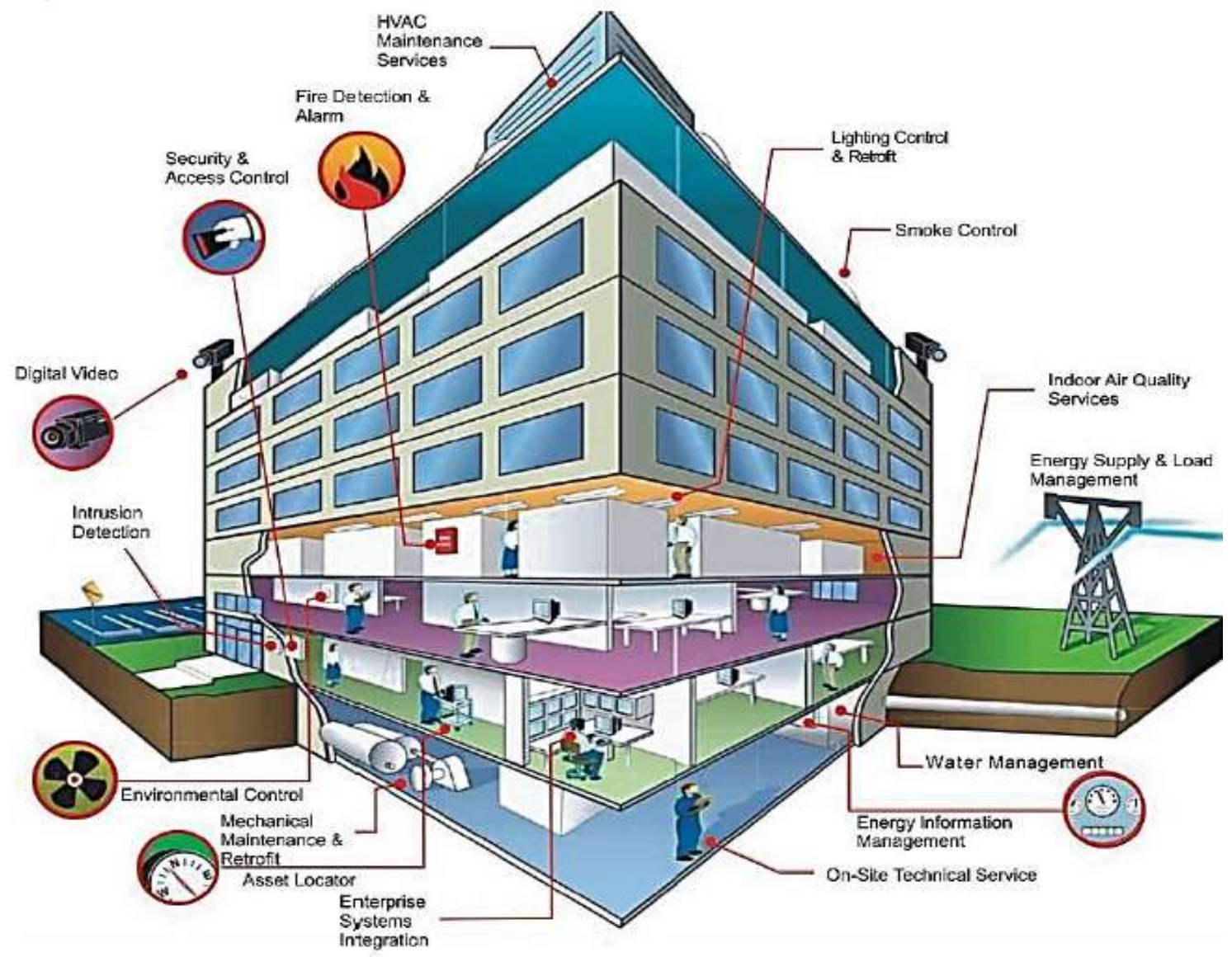

Figure 1. System architecture and IBMS integration

Modern IBMS systems and SCADA system continuously scan sensor data and equipment's operational data and a vast amount of data can be generated related to weather conditions and occupancy levels. An algorithm can be designed to predict how a building will react given a change in the variables associated with its energy performance and the comfort levels provided for its occupants [8,9]. An intelligent building 
is highly adaptable to the changing conditions of its environment in order to provide comfortable living. Simulation tools are used to evaluate the building energy performance, estimate the energy use, and thermal performance dealing with complex thermal phenomena that occurred at building levels. In order to reach the comfortable levels indoor, Fanger's method was used to obtain the initial values of the Predicted Mean Vote (PMV) and the predicted percentage of dissatisfaction (PPD), which can be calculated using a set of equations that depends on several inputs that can be gathered via SCADA system sensors. The PMV value was applied into genetic algorithms to find its optimal value [10-13].

A set of thermal comfort equations and intelligent algorithms are employed to improve search formula for optimization of the factors of PMV to find the value of PPD used as the inputs to predict the value of energy that is used after a specific interval for optimum operation. Controlling and optimizing the power required to manage the HVAC controller through estimated and optimal air temperature value indoor, which can prevent the power used reaching its peak value [14-15].

\section{FANGER'S THERMAL COMFORT APPROACH}

'Thermal comfort' is defined as that situation of judgment which states contentment with the thermal environment. Thermal comfort is a result of an arrangement/revision of factors of both the atmosphere and the human body itself. Fanger established the heat stability and typical thermal comfort, also specified that the form for thermal comfort is that the skin temperature and sweat excretion lie within fine bounds. An expression for optimal thermal comfort can be deduced from the metabolic rate, clothing insulation, and environmental conditions. As well as, the feeling of a person is a function of the physiological strain enforced on him by the thermal environment, the air temperature, the mean radiant temperature, the fractional pressure of water steam in ambient air and the air speed. Fanger forecasts the real thermal feeling of persons in an uninformed environment where the variables might not satisfy the equation; the predicted mean vote (PMV), which is "the difference between the internal heat productions and the heat loss to the actual environment for a man kept at the comfort values for skin temperature and sweat production at the actual activity level". The association between the PMV-index and the predicted percentage of dissatisfaction (PPD) was determined through steady state experiments as shown in Figure 2. This figure shows an equivalent quantity of complaints on the 'warm' side as on the 'cold' side, the curve is identical about the PMV of (0) [16-25].

Fanger's method predicts the average thermal sensation by using an index derived from combine physical variables; (TA: air temperature, VEL: air velocity, TR: mean radiant temperature, and RH: relative humidity), and personal variables; (CLO: clothing insulation and activity level) [26-28]. The inputs (physical variables), obtained by SCADA system are (NP: number of persons, $\mathrm{W}_{\mathrm{HVAC}}$ : heat per second gained by HVAC

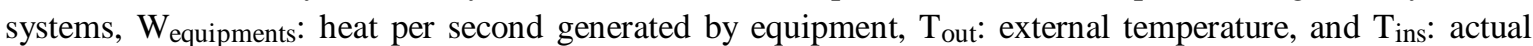
temperature).

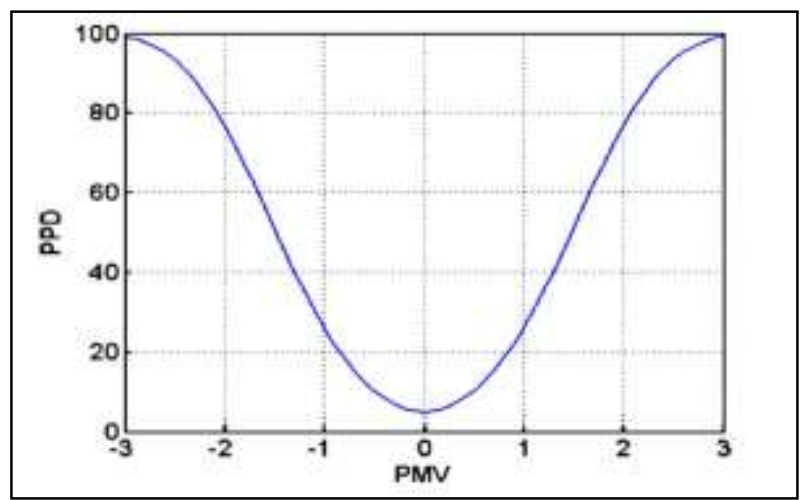

Figure 2. PPD as a function of PMV [28]

In the following, there is a set of equations used to get initial values concerned with different HVAC system variables.

- Saturation Vapor Pressure

$\mathrm{FNPS}=\operatorname{EXP}(16.6536-4030.183 /(\mathrm{TA}+235))$ 
- Clothing Resistance;

$$
\mathrm{ICL}=0.155 \times \mathrm{CLO}
$$

- Metabolic Rate and External Work;

$$
\mathrm{M}=58.15 \times \mathrm{MET} \text { and } \mathrm{W}=58.15 \times \mathrm{WME}
$$

- Internal Heat Production;

$$
\mathrm{MW}=\mathrm{M}-\mathrm{W}
$$

- Clothing Factor; It depends on the value of ICL, and obtained by:

$$
\text { Either FCL }=1+1.29 \times \text { ICL or FCL }=1.05+0.645 \times \text { ICL }
$$

- Forced Convection Conductance;

$$
\mathrm{HCF}=12.1 \times \sqrt{\mathrm{VEL}}
$$

- Air temperature and Mean Radiant Temp. ;

$$
\mathrm{TAA}=\mathrm{TA}+273 \text { and } \mathrm{TRA}=\mathrm{TR}+273
$$

- Estimated Clothing Temperature;

$$
\mathrm{TCLA}=\mathrm{TAA}+(35.5-\mathrm{TA}) /(3.5 \times(6.45 \times \mathrm{ICL}+0.1))
$$

- Clothing Surface Temp;

$$
\mathrm{TCL}=100 \times \mathrm{XN}-273
$$

Where: $\mathrm{XN}$ is the natural convection conductance, which calculated using the following equation and HCF value:

$$
\begin{aligned}
& \mathrm{HCN}=2.38 \times \text { abs }(100 \times \mathrm{XF}-\mathrm{TAA})^{0.25} ; \mathrm{XF}=\mathrm{XN} \\
& \mathrm{XN}=\left(\mathrm{P} 5+\mathrm{P} 4 \times \mathrm{HC}-\mathrm{P} 2 \times \mathrm{XF}^{4}\right) /(100+\mathrm{P} 3 \times \mathrm{HC})
\end{aligned}
$$

- Intermediate values

$$
\begin{aligned}
& \mathrm{P} 1=\mathrm{ICL} \times \mathrm{FCL}, \quad \mathrm{P} 2=3.96 \times \mathrm{P} 1, \quad \mathrm{P} 3=100 \times \mathrm{P} 1, \quad \mathrm{P} 4=\mathrm{P} 1 \times \mathrm{TAA} \\
& \mathrm{P} 5=308.7-0.028 \times \mathrm{MW}+\mathrm{P} 2 \times(\mathrm{TRA} / 100)^{4}
\end{aligned}
$$

The PMV and PPD values obtained using the following equations:

- The predicted mean vote value equation [11]:

$$
\text { PMV = TS x (MW - HL1 - HL2 - HL3 - HL4 - HL5 - HL6) }
$$

Where: TS is the thermal sensation transfer coefficient, which is calculated using the following equation:

$$
\mathrm{TS}=0.303 \times \operatorname{Exp}(-0.036 \times \mathrm{M})+0.028
$$

HL: is the heat loss due to water vapor diffusion through the skin

$$
\text { HL1 }=0.00305 \times(5733-6.99 \times \text { MW }- \text { PA })
$$

HL2: is the heat loss due to sweating that will depend on the value of MW. 
If $\mathrm{MW}$ greater than $(58.15) \Rightarrow \mathrm{HL} 2=0.42 \times(\mathrm{MW}-58.15)$, otherwise; HL2 = 0 .

HL3: is the latent heat loss due to respiration; HL3 $=1.7 \times 10^{-5} \times \mathrm{M} \times$ (5867 - PA)

HL4: is the dry respiration heat loss; HL4 $=0.0014 \times$ M x (34 - TA)

HL5: is the heat loss by radiation from the surface of the clothed body

$$
\text { HL5 = } 3.96 \times \text { FCL } x\left(\mathrm{XN}^{4}-(\mathrm{TRA} / 100)^{4}\right)
$$

HL6: is the heat loss by convection from the surface of the clothed body

$$
\text { HL6 = FCL x HC x (TCL - TA) }
$$

- The predicted percentage of dissatisfied (PPD) was calculated as following, depending on PMV value [29-30]:

$$
\mathrm{PPD}=100-95 \times \operatorname{Exp}\left(-0.03353 \times \mathrm{PMV}^{4}-0.2179 \times \mathrm{PMV}^{2}\right)
$$

An enhanced added features to the Fanger's equations have been developed to estimate the heat power lost per time $\left(\mathrm{W}_{\text {out }}\right)$, heat power generated by occupants $\left(\mathrm{W}_{\text {gen }}\right)$ and the heat transmission coefficient $\left(\mathrm{U}_{\mathrm{m}}\right)$ between the walls of the rooms building which depends on: air blowing, the percentage of the humidity, the quantity of the water inside the walls in a rainy day, the number of occupants (NP), the internal ambient conditions, the external conditions and the structure of the room. The heat lost through walls between rooms


HVAC systems, $\mathrm{W}_{\text {equipment }}$ : Heat generated by equipment, $\mathrm{A}_{\text {out }}=$ Total area of external walls, $\mathrm{Q}_{\text {inf: Heat lost }}$ due to infiltration, $\mathrm{Q}_{\mathrm{i}}$ : Heat lost through internal wall_i.

\section{DESIGN OF TYPICAL HVAC/SCADA SYSTEM APPLICATION OF IBMS}

Mathematical analysis of the thermal behavior of a building generally results in nonlinear models. Adaptive controllers have the ability of self-regulate and adapt to the climate conditions in the buildings by using parameter estimation methods. The transient and steady state performance specifications of the closedloop system can be met using genetic algorithms to optimize controller parameters for HVAC systems [31-33].

The intelligent control of energy systems based on possession a typical intelligent control of air handling units, windows, doors, lighting, HVAC units, and factors associated with comfort, the resident airflow conditions within rooms and building areas and including dissatisfaction with comfort levels to occupants. The self-learning control algorithms can be used in IBMS to react to changes in the variables associated with energy performance including occupant behavior [34-36].

The simulation study of HVAC system is based on designing an exemplar SCADA system intelligent building model. The acquired data used by SCADA system servers will be processed to calculate optimize (PMV), air temperature value (TA) and to control the value of (PMV) at the minimum range. This system is designed to optimize the power used to run HVAC systems and control the comfort level, which is obtained from genetic algorithm after optimization process [37, 38].

The proposed SCADA system design has a set of hypothetical features that cover the following:

- Two controlled rooms with a total volume of (300) $\mathrm{m}^{3}$ for each room.

- Total external surface of (120) $\mathrm{m}^{2}$, and three walls adjacent other rooms with the areas $(30,70$, and 70$) \mathrm{m}^{2}$.

- The heat transmission coefficients of the internal walls are: $(0.4,0.3$, and 0.3$) \mathrm{W} / \mathrm{m}^{2} \cdot \mathrm{K}^{\mathrm{o}}$.

- The around room temperature value is (19) $\mathrm{C}^{\circ}$.

- The heat lost by infiltration is calculated by using the standards [UNI-7979/79], Where the coefficients (c_a) is the window topology assumed as (0.32) with designed model, and (c_b) is the local window condition, which is used in terraced houses as (14) [39].

\section{FANGER'S EQUATIONS IMPLEMENTATION}

The designed model based on set of (variable and fixed) inputs. The variable inputs shown in Table 1, was varied in order to observe its effectiveness on the designed model. The second inputs shown in Table 2, was fixed as constant along simulation process. The equations which are employed to obtain the initial values of PMV, PPD, $\mathrm{U}_{\mathrm{m}}$ and $\mathrm{W}_{\text {out }}$, according to the flowchart shown in Figure 3 (see in appendix) [40]. 
Table 1. Variable model default inputs

\begin{tabular}{lcll}
\hline Variable Inputs & Value & Definition & Units \\
\hline $\mathrm{T}_{\text {act }}$ & 20 & Actual Temperature Indoor & $\mathrm{C}^{\circ}$ \\
$\mathrm{T}_{\text {out }}$ & 6 & Actual Temperature Outdoor. & $\mathrm{C}^{\circ}$ \\
$\mathrm{TR}$ & 26 & Radiant Temperature & $\mathrm{C}^{\circ}$ \\
$\mathrm{NP}$ & 6 & Number of Occupants & -- \\
Vol & 300 & Room Volume & $\mathrm{m}^{3}$ \\
$\mathrm{~W}_{\text {HVAC }}$ & 500 & Heat Power Generated by HVAC & $\mathrm{Watt}^{\circ}$ \\
$\mathrm{W}_{\text {equipment }}$ & 200 & Heat Power Generated by Equipment's & Watt \\
\hline
\end{tabular}

Table 2. Fixed model default inputs

\begin{tabular}{|c|c|c|c|}
\hline Fixed Inputs & Value & Definition & Units \\
\hline VEL & 0.2 & Air Velocity & $\mathrm{m} / \mathrm{s}$ \\
\hline CLO & 1 & Clothing Insulation & $\mathrm{m} 2 . \mathrm{K} / \mathrm{W}$ \\
\hline MET & 1.1 & Metabolic Rate & $\mathrm{W} / \mathrm{m}^{2}$ \\
\hline WME & 0 & External Work & $\mathrm{W} / \mathrm{m}^{2}$ \\
\hline $\mathrm{RH}$ & 50 & Radiant Humidity & $\%$ \\
\hline RHe & 80 & External Radiant Humidity & $\%$ \\
\hline$P_{\text {atm }}$ & 102500 & Atmospheric Pressure & $\mathrm{Pa}$ \\
\hline c_a & 0.32 & Window Topology & --- \\
\hline c_b & 14 & Local Window Condition & --- \\
\hline $\mathrm{U}_{\mathrm{m}}$ & 0.9 & Heat Transmission Coefficient & $\mathrm{W} / \mathrm{m}^{2} \cdot \mathrm{K}^{\mathrm{o}}$ \\
\hline$A_{\text {out }}$ & 60 & Total Area of External Walls & $\mathrm{m}^{2}$ \\
\hline $\begin{array}{l}\mathrm{A}_{\text {ins } 1}, \mathrm{~A}_{\mathrm{ins} 2}, \ldots, \\
\mathrm{A}_{\text {ins } 5}\end{array}$ & $\begin{array}{l}30,100,30,80, \text { and } 20 \\
\text { respectively }\end{array}$ & $\begin{array}{l}\text { Areas of the Wall Surfaces Splitting the Controlled Room from } \\
\text { Around Room 1, 2, 3, } 4 \text { and 5, respectively }\end{array}$ & $\mathrm{m}^{2}$ \\
\hline $\mathrm{U}_{1}, \mathrm{U}_{2}, \ldots, \mathrm{U}_{5}$ & 0.3 & $\begin{array}{l}\text { Wall Transmission Coefficients for Wall 1, 2, 3, } 4 \text { and } 5 \text {, } \\
\text { respectively. }\end{array}$ & $\mathrm{W} / \mathrm{m}^{2} \cdot \mathrm{K}^{\mathrm{o}}$ \\
\hline $\begin{array}{l}\text { Troom } 1, \text { Troom } 2, \\
\ldots . ., \text { Troom } 5\end{array}$ & $\begin{array}{l}19,18,19,21 \text {, and } 19 \\
\text { respectively }\end{array}$ & $\begin{array}{l}\text { Air Temperatures in the Around Room 1, 2, 3, } 4 \text { and 5, } \\
\text { respectively }\end{array}$ & $\mathrm{C}^{\circ}$ \\
\hline
\end{tabular}

\section{GENETIC ALGORITHM FUNCTIONS IMPLEMENTATION}

The genetic algorithm optimization process uses the parameters shown in Table 3, also some of the parameters associated with algorithms were assigned.

Table 3. Genetic algorithm parameters

\begin{tabular}{ll}
\hline Parameter & Definition \\
\hline$G G A P=0.9$ & Generation Gap, identifies the amount of individuals to be nominated per \\
& subpopulation relation to the dimension of the subpopulation \\
XOVR $=1$ & Crossover Rate, the crossover rate is not used so its value selected as (1). \\
$M U T R$ & Mutation Rate \\
$M A X G E N=30$ & Max no. of generations \\
$I N S R$ & Insertion Rate \\
SUBPOP $=10$ & No. of Subpopulations \\
$M I G G E N$ & No. of Gens \\
NIND & No. of Individuals / Subpop \\
\hline
\end{tabular}

The genetic algorithm is implemented using the following functions and parameters:

- Creation of the initial population; using (Crtrp) function to produce a matrix (Chrom) of chromosomes. The subpopulations were directly calculated using (feval).

- Fitness value assignment to whole population; the fitness value function is the (ranking), each individual objective values in $(o b j V)$ are graded independently and the consequential sets of fitness values returned in the vector (FitnV).

- Selection of Individuals from population; Individuals are nominated for refinement autonomously using the selection (select) utility, each subpopulation forms the matrix ( $\mathrm{SelCh}$ ) holding all the couples of individuals to be recombined.

- Recombine selected individuals; the recombination utility, (recdis), is used to join up couples of individuals within each subpopulation of ( $\mathrm{SelCh})$.

- Offspring mutation; using (mutate) utility will execute mutations of individuals from population, $\left(M U T \_F\right)$ is a series, the GA mutation task requires the field descriptor, (FieldD), so that the effect of mutation will not yield values exterior the limits of the resolution variables. 
- Calculations of the objective function for offspring; the utility (feval) is used to compute the objective values of all the offspring (objVoff).

- Insertion of the best offspring replacing worst parents; offspring can be inserted into the suitable subpopulations by using (reins) utility.

- Predicted Mean Vote values loop selection; as a final step to get the optimal values of PMV and TA.

- The termination condition used in optimization process; is the number of generations, so the algorithm stops when the number of generations reaches the max value.

The flowchart shown in Figure 4 (see in appendix) shows the steps to obtain the (PMV) and (TA) values as optimum values using genetic algorithm. The block diagram in Figure 5 shows the model inputs and the flow of the modelling and optimization process for integrated HVAC/SCADA system application [41, 42].

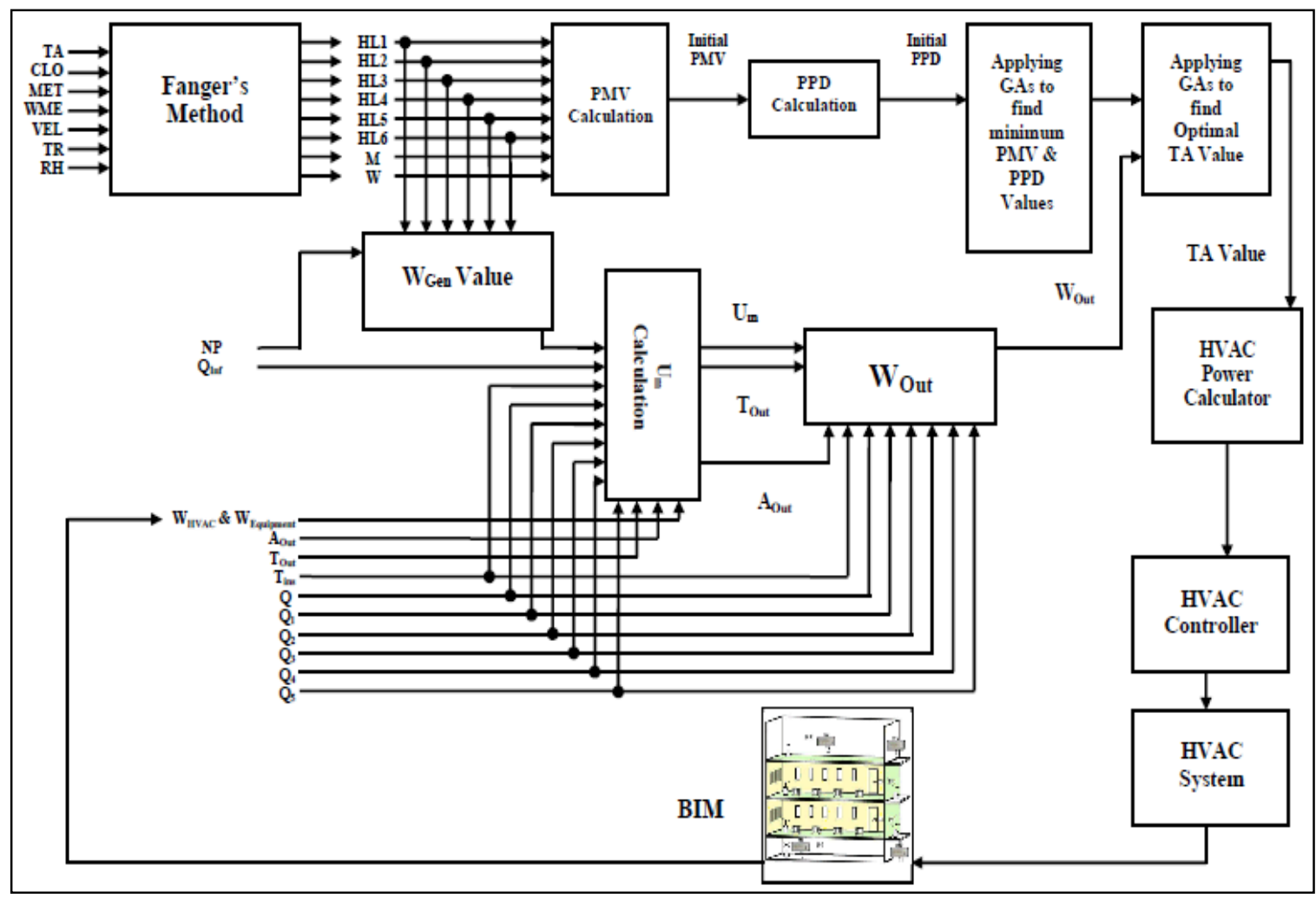

Figure 5. The block diagram of the modelling and optimization pocess for integrated HVAC/SCADA system

\section{SIMULATION OF ENERGY CONSUMPTION AND THERMAL COMFORT OF IBMS}

The adjustable control systems are necessary in HVAC system because the features of the process change constantly by effect of the variation in the environment and occupation of the construction.

\subsection{Predicted mean vote (PMV) values behavior}

The PMV values obtained from simulation process scenarios, were plotted in Figure 6. It shows that the peak values of PMV are at the points (D and E). The scenario is concerned with radiant temperature and number of occupants, respectively. The decreasing of the TR value causes sensible increase in the value of TA, this change, is attempting to keep the comfort user's environment, and so the value of air temperature will be increased. Point (E) shows that increasing the number of occupants of indoors to (14), will affect the value of PMV and the heat power generated by occupants at starting point. The obtained PMV values for the other scenarios are less effective in the system and are considered to be very close to the comfortable levels to keep PMV value at its natural (zero) point.

\subsection{The GA parameters selection and PMV behavior}

The simulation results shown in Figure 7, named G1 presents PMV values with number of generations (MAXGEN) equal to (20), the second curve G2 presents PMV values when the number of generations was 
(30). To get PMV value covering zero and achieving the best comfortable level, so the max number of generations was set to (30) generations.

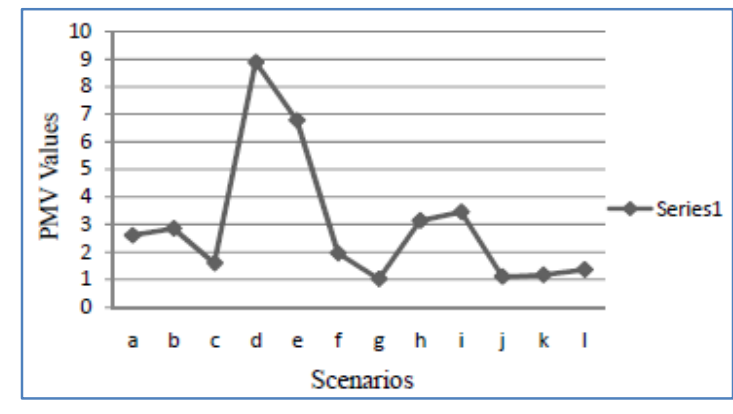

Figure 6. Predicted mean vote (PMV) values



Figure 7. PMV behavior when using different number of generations (MAXGEN)

\subsection{Results and discussions of predicted $T A, W_{\text {gen }}$, and $W_{\text {out }}$ values}

System simulation scenarios have been accomplished. In each scenario one of the model inputs variable was changed in order to observe its impression on the optimization process. The changes in TA, $\mathrm{W}_{\text {gen }}$, and $\mathrm{W}_{\text {out }}$ at (time $=$ zero) and after expected time were observed. The simulation results were shown in Figure 8 (see in appendix) and summary of the optimization process result shown in Table 4 (see in appendix). An acceptable comfort environment are obtained as shown in Figure 8 (a). In scenario (A) all the system input variables were set to standard values. The results were found as model outputs are: PMV $=2.6 \times 10^{-6}, \mathrm{TA}=$ $21.27 \mathrm{C}^{\circ}$, which are very close to the user's comfort level. The TA and the PMV values are according to ISO and Fanger's approach, so the comparison among other different simulation scenarios will consider this case as a reference case. The simulation results shown in Figure 8 (b), reveal that increase the actual temperature inside the controlled room will increase both $\mathrm{W}_{\text {out }}$ and $\mathrm{W}_{\text {gen }}$ linearly. Comparing these results with the first results obtained in Figure 8 (c) show that the increase of the external temperature $T_{\text {out }}$ will affect $\mathrm{W}_{\text {out }}$ and $\mathrm{W}_{\text {gen }}$. Table 4 shows that the increasing of $\mathrm{T}_{\text {Indoor }}$ leads to increase $\mathrm{W}_{\text {gen }}$ and $\mathrm{W}_{\text {out }}$ and vice versa. When the radiant temperature TR was decreased to $7 \mathrm{C}^{\circ}$ for example, the values of $\mathrm{W}_{\text {out }}$ and $\mathrm{W}_{\text {gen }}$ are decreased. The radiant temperature increased the air temperature value to be at its highest level, TA $=25.68 \mathrm{C}^{\circ}$ shown in Figure 8 (d). Figure 8 (e) shows that when the number of occupants NP of the building is increased the value of $\mathrm{W}_{\text {gen }}$ will be increased. This leads to the decrease of $\mathrm{W}_{\text {out }}$ to keep the user comfort level. The simulation results when considering the controlled room empty (Number of occupants $=0)$ and $\left(\mathrm{W}_{\mathrm{gen}}=0\right)$ is shown in Figure $8(\mathrm{f})$, where $\mathrm{W}_{\text {out }}$ will increase to get heat from surrounding rooms. When the number of occupants is one, the person is able to generate a maximum heat of (126) Watts, and the $\mathrm{W}_{\text {out }}$ due to one person is about (280) Watts as shown in Figure $8(\mathrm{~g})$. To study the effects of room volume, Figure 8 (h) shows that the increase of the volume affected the value of PMV to keep the comfort level, PMV= $3.1 \times 10^{-6}$. $\mathrm{W}_{\text {out }}$ becomes greater than $\mathrm{W}_{\text {gen }}$ to keep natural temperature indoors by decreasing the power required to run HVAC system as shown in Figure 8 (i) and Table 4. The simulation results in Figure 8 (j) show that the factor $\mathrm{W}_{\text {equipments }}$ has a minor effect on the value of $\mathrm{W}_{\text {out }}$ and $\mathrm{W}_{\text {gen }}$. The decrease in the value of $\mathrm{W}_{\text {equipments }}$ to 50 Watts, will result in a small change in the value of $\mathrm{W}_{\text {out }}$ as shown in Table 4 . The value of TR was increased to up to $32 \mathrm{C}^{\circ}$ while $\mathrm{W}_{\text {out }}$ is increased above the $\mathrm{W}_{\text {gen }}$ value as shown in Figure $8(\mathrm{k})$. $\mathrm{W}_{\text {out }}$ has reached its maximum value (greater than $\mathrm{W}_{\text {gen }}$ ) by increasing the HVAC system power. Figure 8 (l) shows that it is going to increase continuously.

\section{CONCLUSIONS}

The intelligent building management system and supervisory control and data acquisition systems are highly adaptable to the change conditions of the environment in order to provide comfortable living. The use of genetic algorithm for adaptive control of energy controlling processes offered the greatest prospect of success in relation to minimizing energy use. The major sources of uncertainties in the expected air temperature value is the occupant's number and their behavior as a consequence of increased Predicted Mean Vote value. The simulation results shows that the air temperature value and predicted mean vote value are very close to the optimal and standard values according to Fanger's approach. Using genetic algorithm achieved optimum results, confirm the formulation of the objective function to find the optimal value of predicted mean vote, the choice of maximum number of generations, the energy optimization equation, enhance the performance of the 
designed model, and keep the PMV near to zero to maintain the user's comfortable environments. Using optimization function in conjunction with energy associate tools will enable the calculation of the optimal set points for system components in real time acquired by SCADA system, this will lead to minimize the system energy usage.

\section{APPENDIX}
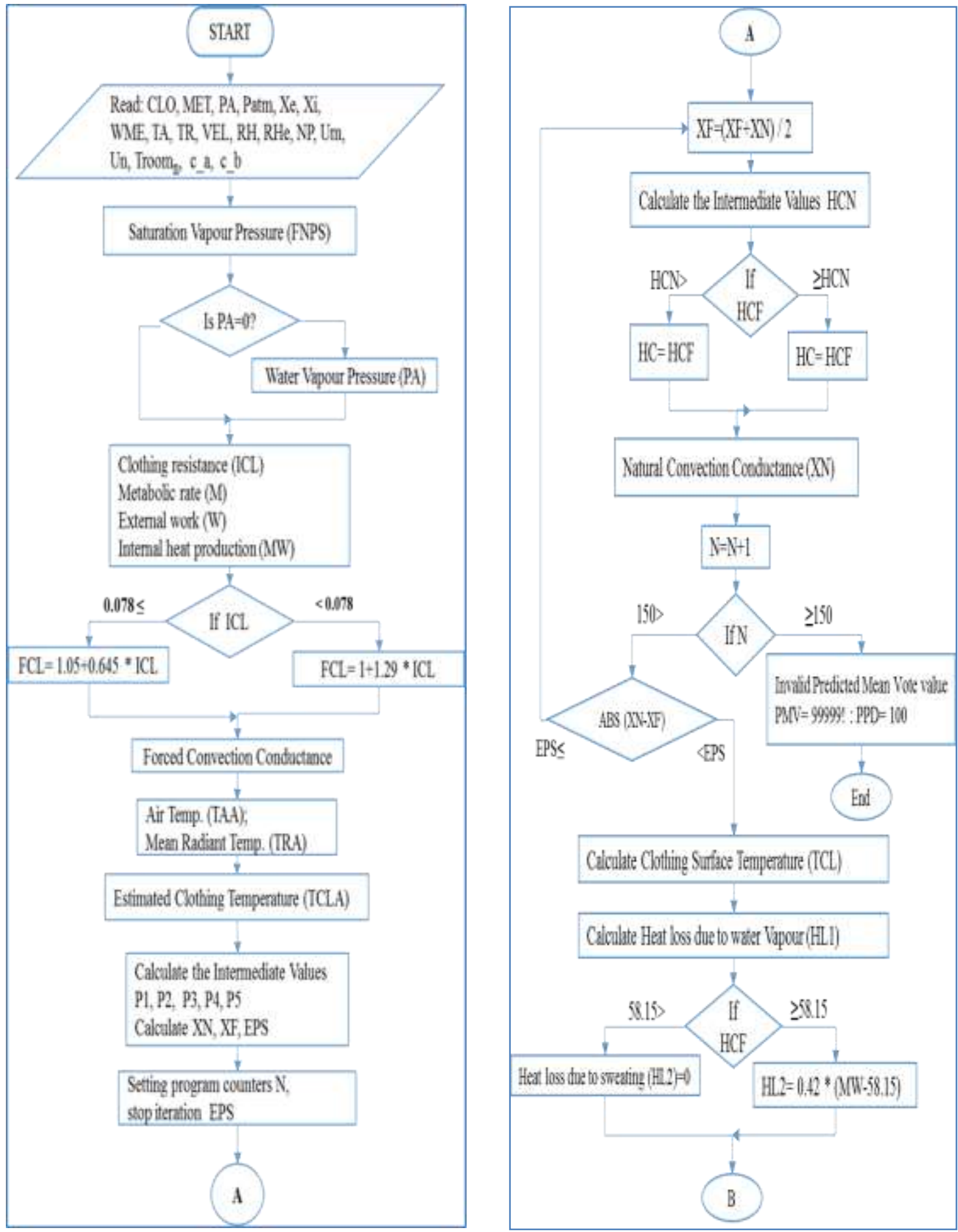


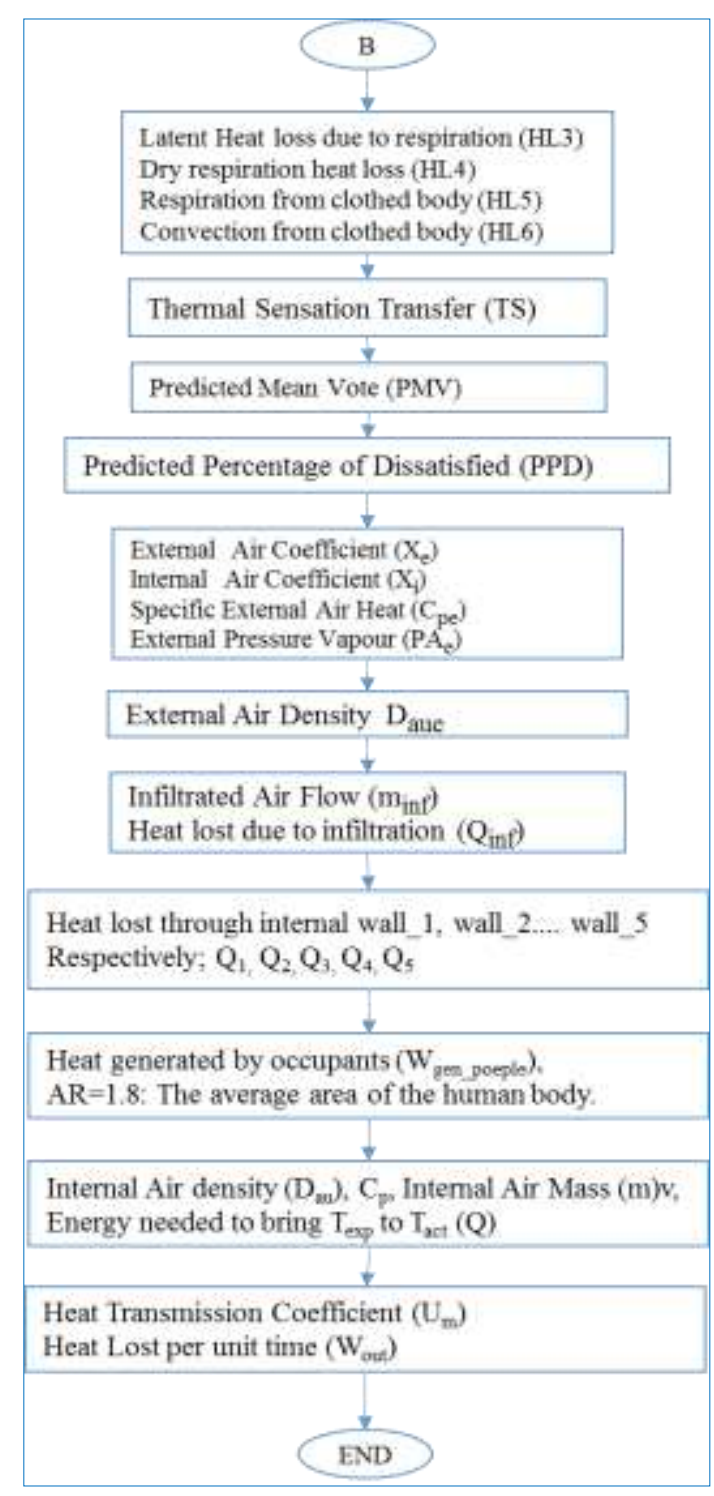

Figure 3. Flowchart for the Calculation of PMV, PPD, and $\mathrm{U}_{\mathrm{m}}$ using Fanger's approach (continue)



Figure 4. PMV and TA optimization flowchart using genetic algorithm 


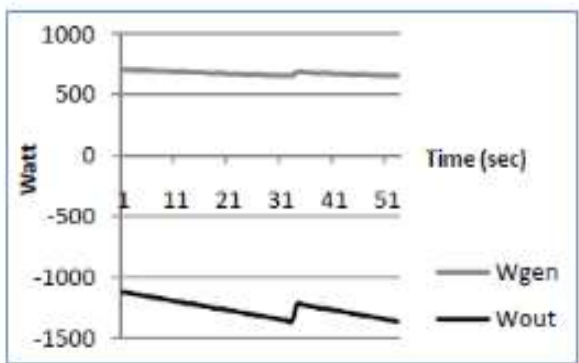

(a) Set system input variables to the standard appropriate values: $\mathrm{PMN}=2.606^{*} 10^{-4}, \quad \mathrm{TA}=21.27 \mathrm{C}^{\circ}$

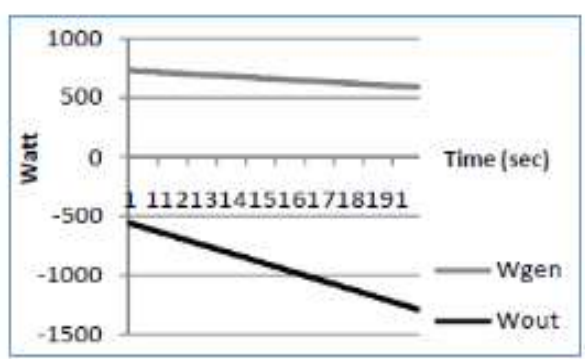

(c) Increasing the extemal temp (Tout) by $6 \mathrm{C}^{\circ}$. $\mathrm{PMV}=1.602 * 10-6, \quad \mathrm{TA}=21.27^{\circ} \mathrm{C}^{\circ}$

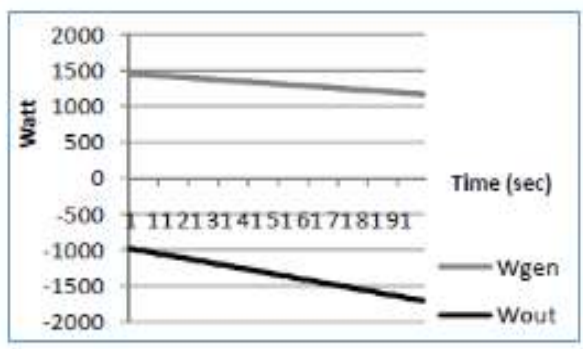

(e) The number of occupants (NP) was increased by (8) occupants: $\mathrm{PMN}=6.7821^{\circ} 10-6, \quad \mathrm{TA}=21.27 \mathrm{C}^{\circ}$



(b) The actual temp (Tact) was increased by $5 \mathrm{C}^{3}$ : $\mathrm{PMN}=2.869^{4} 10-6, \mathrm{TA}=21.27 \mathrm{C}^{\circ}$

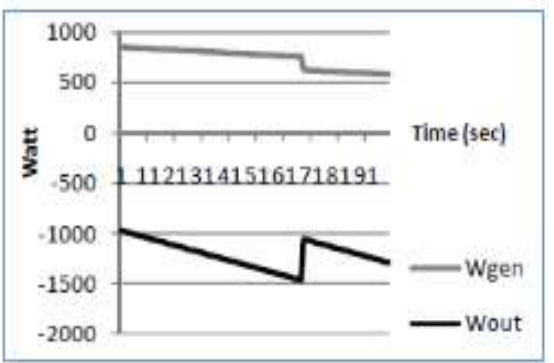

(d) The radiant temp (TR) was decreased by $7 \mathrm{C}^{\text {s. }}$ $\mathrm{PMV}=8.883^{*} 10-6, \mathrm{TA}=25.68 \mathrm{C}^{\circ}$

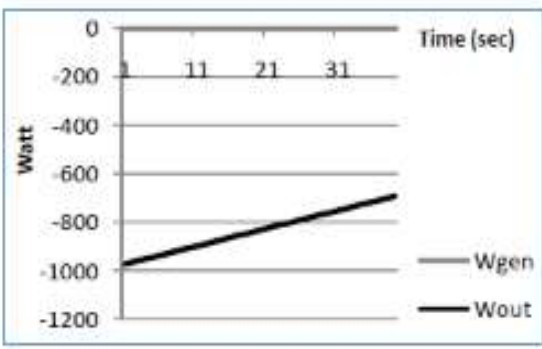

(f) Assuming that the office is empty, (NP) $=0$ : PMV $=1.9576^{*} 10-6, \quad \mathrm{TA}=21.27 \mathrm{C}^{2}$

Figure 8. (a-f ) System simulation scenarios of process optimization for HVAC/SCADA

Table 4. An outline of the simulation results obtained from set of scenarios.

\begin{tabular}{|c|c|c|c|c|c|c|c|c|c|c|c|c|}
\hline Scenario $* *$ & $\mathrm{~A}$ & $\mathrm{~B}$ & $\mathrm{C}$ & $\mathrm{D}$ & $\mathrm{E}$ & $\mathrm{F}$ & $\mathrm{G}$ & $\mathrm{H}$ & $\mathrm{I}$ & $\mathrm{J}$ & $\mathrm{K}$ & $\mathrm{L}$ \\
\hline $\begin{array}{l}\text { Temperature } \\
\text { at }(\mathrm{t}=0)\left(\mathrm{C}^{\circ}\right)\end{array}$ & 21 & 25 & 20 & 20 & 20 & 20 & 20 & 20 & 20 & 20 & 20 & 20 \\
\hline Temperature & & & & & & & & & & & & \\
\hline $\begin{array}{l}\text { after expected } \\
\text { time }\left(\mathrm{C}^{\circ}\right)\end{array}$ & 22.6 & 22.6 & 24.9 & 24.9 & 25.7 & 18.1 & 19 & 22.6 & 20.9 & 21.8 & 24.55 & 21.9 \\
\hline $\begin{array}{l}\text { Expected Time } \\
\text { (Min) }\end{array}$ & 72 & 72 & 70 & 70 & 59 & 89 & 83 & 120 & 124 & 121 & 117 & 117 \\
\hline $\begin{array}{l}\text { Wgen } \\
\text { (Watt) }\end{array} \quad(\mathrm{t}=0)$ & 699 & 581 & 728 & 858 & 1456 & 0 & 121 & 728 & 728 & 728 & 727 & 609 \\
\hline $\begin{array}{l}\text { Wgen (expected } \\
\text { time) (Watt) }\end{array}$ & 625 & 625 & 584 & 584 & 1121 & 0 & 126 & 625 & 702 & 677 & 594 & 554 \\
\hline $\begin{array}{l}\text { Wout } \quad(t=0) \\
\text { (Watt) }\end{array}$ & -1121 & -1718 & -560 & -972 & -973 & -973 & -973 & -973 & -973 & -973 & -972 & -973 \\
\hline $\begin{array}{l}\text { Wout (predicted } \\
\text { time) (Watt) }\end{array}$ & -1359 & -1359 & -1288 & -1288 & -1823 & -693 & -825 & -1359 & -1106 & -1232 & -1650 & -1254 \\
\hline
\end{tabular}

$\begin{array}{lll}\text { (A) Default Values; } & \text { (B) Changing Tact to } 25 \mathrm{C}^{\circ} ; & \text { (C) Changing Tout to } 12 \mathrm{C}^{\circ} \text {; }\end{array}$

** Scenario

(D) Radiant Temperature $=19 \mathrm{C}^{\circ}$; $\quad$ (E) Number of Occupants $=14$; $\quad$ (F) Number of Occupants $=0$;

(system variable

(G) Number of Occupants $=1 ; \quad$ (H) Room Volume $=500 \mathrm{~m}^{3}$;

(I) $\mathrm{W}_{\mathrm{HVAC}}=200 \mathrm{Watt}$;

setting)

(J) Wequipments $=50$ Watt.; (K) $\mathrm{W}_{\text {HVAC }}=850$ Watt.; (L) Radiant Temperature $=32 \mathrm{C}^{\circ}$ 


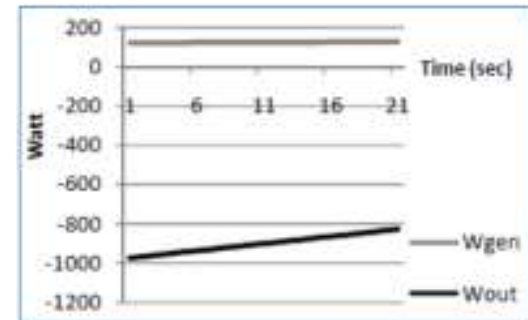

(8) (NP) was soumedas (1) ocapont PMV-10277*10-6 $\mathrm{IA}=2127 \mathrm{C}^{\prime}$

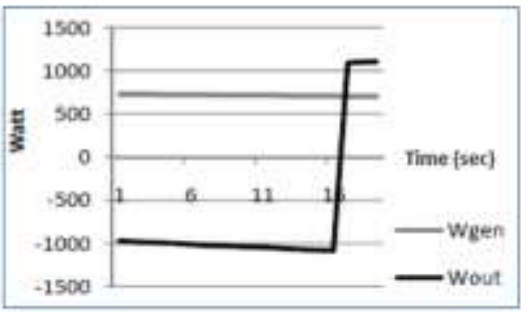

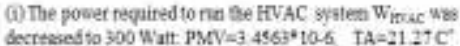



(a) TR was itcreased up to $32 \mathrm{C}:$ : PSNin $1.1734+10-6$ $T A=17.12 \mathrm{C}^{\circ}$

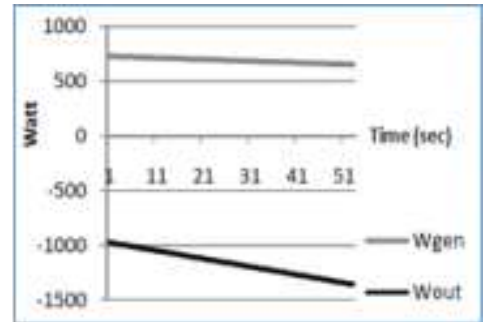

Thi) The vofume of the room (Vati eas cliaped by 200 en: $P \mathrm{MNV}=3.1424 * 10-6, \mathrm{TA}=21.27 \mathrm{C}$

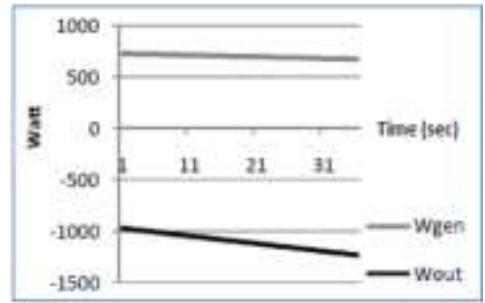

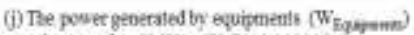

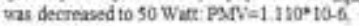
$\mathrm{IN}=21.27 \mathrm{C}^{\mathrm{C}}$



(1) Wrae was itcreased top to 590 Watt DMVV=1 3647"10.7, Th-21 27C

Figure 8. (g-l) System simulation scenarios of process optimization for HVAC/SCADA system

\section{REFERENCES}

[1] ASHRAE Standard 62.2-2003, "Ventilation and acceptable indoor air quality in low-rise residential buildings," 2003.

[2] Randy Dennison, "A Pre-SCADA System Assessment," Research Faculty EPG Companies Inc., Bulletin 7405b, 2004.

[3] A. Eruano, P. M. Ferreira, "Neural Network based HVAC Predictive Control," Proceedings of the 19th World Congress the International Federation of Automatic Control Cape Town, South Africa. 2014.

[4] A. Afram, F. J. Sharifi, A. S. Fung, K. Raahemifar, "Artificial neural network (ANN) based model predictive control (MPC) and optimization of HVAC systems: A state of the art review and case study of a residential HVAC system," Energy and Buildings, vol. 141, pp. 96-113, 2017.

[5] K. E. Reena, A. T. Mathew, L. k. Jacob, "A flexible control strategy for energy and comfort aware HVAC in large buildings," Building and Environment, vol. 145, pp. 330-342, 2018.

[6] S. Lee,, J. Joe,, P. Karava,, I. Bilionis, A. Tzempelikos, " Implementation of a self-tuned HVAC controller to satisfy occupant thermal preferences and optimize energy use," Energy and Buildings, vol. 194, pp. 301-316, 2019.

[7] Ardehali, M. M. and Smith T.F., "Evaluation of variable volume and temperature HVAC system for commercial and residential buildings," Energy Conversion and Management, vol. 37, pp. 1469-1479, 1996.

[8] G.J. Rios-Moreno, M. Trejo-Perea, R. Castaneda-Miranda, V.M. Hernandez-Guzman and G. Herrera-Ruiz, "Modelling Temperature in Intelligent Buildings by Means of Autoregressive Models," Faculty of Engineering, Universidad Autonoma de Querétaro, Cerro de las Campanas s/n, CP 76010, Querétaro, México, 2006.

[9] C. Gallo, M. Sala, and A.A.M. Sayigh, "Architecture: Comfort and Energy," Renewable and Sustainable Energy Reviews 2, Elsevier Science, 1998.

[10] James A. White and Howard Reichmuth, "Simplified Method for Predicting Building Energy Consumption Using Average Monthly Temperature," Energy Conversion Engineering Conference, vol. 3, pp. 1834-1839, 1996.

[11] Italian normative Standards [UNI - 7979/79], "Classification of Window frames Depending on the Air Permeability, Water Tightness and Wind Resistance," 2000.

[12] S. N. Sivanandam and S. N. Deepa, "Introduction to Genetic Algorithms," Springer, 2008.

[13] A. A. Malik, et al., "Statistical analysis using taguchi method for wind turbine in ducting system," Indonesian Journal of Electrical Engineering and Computer Science, vol. 15, no. 1, pp. 26-33, 2019. 
[14] W. Tariq, et al., "A Review on ESCO's Challenges and Project Management as a Solving Tool," Indonesian Journal of Electrical Engineering and Computer Science, vol. 12, no. 1, pp. 269-274, 2018.

[15] T. S. Gunawan, et al., "Prototype Design of Smart Home System using Internet of Things," Indonesian Journal of Electrical Engineering and Computer Science, vol. 7, no. 1, pp. 107-115, july 2017.

[16] A. A. Alahmadi, "Developing a wireless real-time automated home approach utilizing NI MyRIO microcontroller board and LabVIEW platform," Indonesian Journal of Electrical Engineering and Computer Science, vol. 16, no. 3, pp. 1273-1278, 2019.

[17] K. Luechaphonthara and A. Vijayalakshmi, "IOT based application for monitoring electricity power consumption in home appliances," International Journal of Electrical and Computer Engineering (IJECE), vol. 9, no. 6, pp. 49884992, 2019.

[18] T. S. Gunawan, et al., "Performance Evaluation of Smart Home System using Internet of Things," International Journal of Electrical and Computer Engineering (IJECE), vol. 8, no. 1, pp. 400-411, 2018.

[19] M. Hannats, et al., "UDP Pervasive Protocol Integration with IoT for Smart Home Environment using LabVIEW," International Journal of Electrical and Computer Engineering (IJECE), vol. 8, no. 6, pp. 5342-5350, 2018.

[20] B. M. Amine1, et al., "Smart Home Automation System Based on Arduino," International Journal of Robotics and Automation (IJRA), vol. 7, no. 4, pp. 215-220, dec. 2018.

[21] F. del Ama Gonzalo, et al., "Non-intrusive electric power monitoring system in multipurpose educational buildings," International Journal of Power Electronics and Drive System (IJPEDS), vol. 10, no. 3, pp. 1297-1307, sep. 2019.

[22] J. Chaisan, et al., "The Optimization of Hybrid Air Ventilation System Combined with Silica Gel and Thermoelectric Using Monitoring Control," International Journal of Power Electronics and Drive System (IJPEDS), vol. 9, no. 4, pp. 1624-1633, dec. 2018.

[23] A. Mayub, et al., "Implementation smart home using internet of things," TELKOMNIKA Telecommunication Computing Electronics and Control, vol. 17, no. 6, pp. 3126-3136, dec. 2019.

[24] D. Imededdin, et al., "Design and implementation of low power consumption wireless sensor node," TELKOMNIKA Telecommunication Computing Electronics and Control, vol. 17, no. 6, pp. 2729-2734, dec. 2019.

[25] E. I. Agustin, et al., "Voice recognition system for controlling electrical appliances in smart hospital room," TELKOMNIKA Telecommunication Computing Electronics and Control, vol. 17, no. 2, pp. 965-972, April 2019.

[26] Z. G. Faisal, et al., "Design and realization of motion detector system for house security," TELKOMNIKA Telecommunication Computing Electronics and Control, Vol. 17, No. 6, pp. 3211-3217, Dec. 2019.

[27] G. C. Cardarilli, et al., "Energy Consumption Saving in Embedded Microprocessors Using Hardware Accelerators," TELKOMNIKA Telecommunication Computing Electronics and Control, vol. 16, no. 3, pp. 1019-1026, June 2018.

[28] V. Kanakaris, et al., "Power consumption analysis on an IoT network based on wemos: a case study," TELKOMNIKA Telecommunication Computing Electronics and Control, vol. 17, no. 5, pp. 2505-2511, Oct. 2019.

[29] A. N. Azlina, et al., "Intelligent home automated system," Indonesian Journal of Electrical Engineering and Computer Science, vol. 15, no. 2, pp. 733-742, 2019.

[30] N. I. Ramli, et al., "Investigating thermal comfort for the classroom environment using IoT," Indonesian Journal of Electrical Engineering and Computer Science, vol. 9, no. 1, pp. 157-163, 2018.

[31] G. C. Cardarilli, et al., "Approximated computing for low power neural networks," TELKOMNIKA Telecommunication Computing Electronics and Control, vol. 17, no. 3, pp. 1236-1241, 2019.

[32] B. D. Argo, et al., "A fuzzy micro-climate controller for small indoor aeroponics systems," TELKOMNIKA Telecommunication Computing Electronics and Control, vol. 17, no. 6, pp. 3019-3026, 2019.

[33] A. A. Malik, et al., "Statistical analysis using taguchi method for wind turbine in ducting system," Indonesian Journal of Electrical Engineering and Computer Science, vol. 15, no. 1, pp. 26-33, 2019.

[34] R. F. Mustapa, et al., "Energy consumption prediction through linear and non-linear baseline energy model," Indonesian Journal of Electrical Engineering and Computer Science, vol. 17, no. 1, pp. 102-109, 2019.

[35] X. K. Dang, et al., "Analyzing the sea weather effects to the ship maneuvering in Vietnam's sea from BinhThuan province to Ca Mau province based on fuzzy control method," TELKOMNIKA Telecommunication Computing Electronics and Control, vol. 16, no. 2, pp. 533-543, 2018.

[36] N. A. Wahab, et al., "Artificial neural network-based technique for energy management prediction," Indonesian Journal of Electrical Engineering and Computer Science, vol. 17, no. 1, pp. 94-101, 2019.

[37] J. W. Moon and S. K. Jung, "Development of a thermal control algorithm using artificial neural network models for improved thermal comfort and energy efficiency in accommodation buildings," Applied Thermal Engineering, vol. 103, pp. 1135-1144, 2016.

[38] T. Chaudhuri, et al., "A feedforward neural network based indoor-climate control framework for thermal comfort and energy saving in buildings," Applied Energy, vol. 248, pp. 44-53, Aug 2019.

[39] H. J. Yoon, et al., "Prediction of thermal environment in a large space using artificial neural network," Energies, vol. 11, no. 2, pp. 418-432, 2018.

[40] Z. Deng and Q. Chen, “Artificial neural network models using thermal sensations and occupants' behavior for predicting thermal comfort," Energy and Buildings, vol. 174, pp. 587-602, 2018.

[41] R. Escandón, et al., "Thermal comfort prediction in a building category: Artificial neural network generation from calibrated models for a social housing stock in southern Europe," Applied Thermal Engineering, vol. 150, pp. 492-505, 2019.

[42] H. H. Bakr, et al., "A neuro-fuzzy sugeno-style HVAC control system for balancing thermal comfort and energy consumption," Proceedings of the 9th International Joint Conference on Computational Intelligence, pp. 419-426, 2017. 